\title{
The perspectives of final year medical students for one year training experience in clinical skills laboratory in Erbil
}

\begin{abstract}
Nazdar E. AlKhateeb $* \quad$ Jalal H. Salih $* * \quad$ Nihad Shabela $* * \quad$ Nazar P. Shabila $* * *$
Abstract

Background and objective: The aim of this study was to provide a general description of a new experience of introducing teaching in clinical skills laboratory to the final year students of Hawler College of Medicine and to assess the students' perspectives of one year training experience in the newly established clinical skills laboratory.

Methods: This study was based on a self-administered questionnaire survey of 79 final year medical students. The questionnaire included 31 statements related to the physical environment of the clinical skills laboratory, duration of clinical skills practice, quality of clinical skills teaching and usefulness of clinical skills laboratory. Each statement was rated on a five-point Likert scale.

Results: Most students were satisfied with the location of the clinical skills laboratory $(62.8 \%)$ and appropriateness of educational atmosphere of the laboratory (59\%). Less than half of the students were satisfied with adequacy and appropriate use of educational equipments. Students had concerns about the short duration of clinical skills practice and unavailability of structured and well explained guidelines (36.7\%). Majority of students indicated that they prefer to take sessions in the skills laboratory and practice before dealing with real patients $(78.1 \%)$ and have earlier integration of teaching in clinical skills laboratory in the medical study curriculum $(71.8 \%)$.

Conclusion: This short and new experience of training in clinical skills laboratory was positively recognized in general. The study identified shortcomings in a number of aspects that need to be addressed to improve the experience.
\end{abstract}

Keywords: Medical students; Clinical skills; Satisfaction; Equipment.

\section{Introduction}

There is growing international interest in teaching clinical skills in a variety of context, one of which is clinical skills laboratories. Many developing countries seek to establish clinical skills laboratories to ensure effective and reliable skills teaching. ${ }^{1}$ The primary role of clinical skills training is that it offers an innovative learning method that efficiently fills the gap between theoretical knowledge and clinical practice. An important feature of teaching in skills laboratories is that it is independent on the availability of patients. ${ }^{2}$ Teaching clinical skills is now increasingly dependent on the use of anatomically realistic models or manikins, which allow students to safely practice key clinical skills until they become confident enough to work with real patients. ${ }^{3,4}$ After decades of instability, the medical teaching sector in Iraq has been left isolated from the global academic community and has missed out on valuable knowledge-sharing opportunities. In Iraq, the opportunity of establishing and using clinical skills laboratories has often been very limited. ${ }^{5}$ Like many other countries, ${ }^{6}$ it is possible for a student in Iraq to qualify as a doctor without even performing practical skills as intravenous cannulation, and then learn it during the internship. The conventional format of teaching medical

* Department of Pediatrics, College of Medicine, Hawler Medical University, Erbil, Iraq

* Department of Surgery, College of Medicine, Hawler Medical University, Erbil, Iraq

* Department of Community Medicine, College of Medicine, Hawler Medical University, Erbil, Iraq 
students (teacher-centered learning) that is largely applied in Iraq is frequently unstructured. The acquisition of skills is left largely to chance and is subject to little quality control, students are inadequately monitored and feedback is seldom given. Thus, the medical students are usually sent to emergency units or other clinical placement sites to practice directly on patients, without having the benefit of being assessed in the safe environment of a skills facility. ${ }^{5}$ This study aimed to provide a general description of a new experience of introducing teaching in clinical skills laboratory to the final year students of Hawler College of Medicine and to assess the students' perspectives of one year training experience in the newly established clinical skills laboratory.

\section{Description of the clinical skills laboratory}

Through the DelPHE (Development Partnerships in Higher Education)-Iraq project and in collaboration with Cardiff University, a simulation laboratory for basic clinical skills teaching was developed at Hawler Medical University. Through the project, the laboratory was equipped with basic skills models while Cardiff University provided the necessary educational materials and guidelines for specific skills training in addition to providing a number of training sessions to the tutors and students of Hawler Medical University. The newly established clinical skills laboratory is temporarily located in the College of Pharmacy building until new space will be allocated in the College of Medicine. The class size is typically between 10 and 15 students supervised by one tutor. Each session lasts for around two hours. A typical session starts by demonstrating the skill by the tutor, followed by repeating the demonstration with clarifying important points and rationale for each step. Then all the students practice the learnt skill under instructor's observation. Medical students were involved in clinical skills sessions on a number of medical procedures in three main topics of surgery, pediatrics and obstetrics and gynecology. The internal medicine topic was not included as relevant training tools for this topic were not provided at the time of the study. The medical procedures included taking blood sample, intravenous cannulation, urinary catheterization, suturing skin wound, pelvic examination, pediatric basic life support, hand rubbing and management of foreign body aspiration in infant and older children. During the academic year 2012-2013, teaching in the clinical skills laboratory has been integrated to the curriculum of the final year medical students. In the initial stage of its establishment, only simple training models and of limited quantities were made available due to the small sized collaborative project and limited available budget at Hawler College of Medicine.

\section{Methods}

This study was based on a self-administered questionnaire survey of medical students in Hawler College of Medicine. All the final year medical students were invited to participate in the study. A four item questionnaire was developed to assess medical students' perspectives and experiences of clinical skills teaching in the newly established clinical skills laboratory. The questionnaire was developed based on a small open-end questionnaire survey involving 30 medical students and literature review. ${ }^{7,8}$ The literature review that was used to design the questionnaire was guided by two aims. Firstly, it tried to determine the main potential concerns of medical students with introduction of teaching in clinical skills laboratories in a developing country context. Secondly, it sought to identify the main challenges that could potentially face such experience. The questionnaire assessed students' perspectives of the physical environment of the clinical skills laboratory (six statements), duration of clinical skills practice (three statements), quality of clinical skills teaching (four statements on organization of sessions and five statements on instructors' performance) 
and usefulness of clinical skills laboratory (13 statements). Each statement was rated on a five-point Likert scale (ranging from 1 , strongly disagree, to 5 , strongly agree). The Likert scale of psychometric assessment was used rather than other testing tools to provide the participants with an open opportunity to express their potential diverse perspectives of this new experience. The survey instrument was tested to assess comprehensiveness, adequacy, clarity and relevance of items. Thus, the instrument was subjected to two cycles of modifications based on feedback from participants. The questionnaire was directly dispatched to the selected sample of medical students with a brief description of the purpose of the study, anonymity of the survey, clarification of the type of questions and a request for an informed consent. The data was collected at the end of study year (during the month of June 2013). This study was approved by the Research Ethics Committee of Hawler College of Medicine. Statistical analysis involved application of descriptive statistics. In data analysis and for the purposes of discussion, we combined the positive ratings "agree" and "strongly agree" and negative ratings "disagree" and "strongly disagree". Therefore, a three-point scale was used for reporting the findings; "strongly agree/agree", "no opinion/neutral" and "strongly disagree/disagree". Missing data for each statement were not included. Data were analyzed using SPSS version 18.0 software (SPSS Inc, Chicago, IL).

\section{Results}

Of 115 final year medical students, $79(68.7 \%)$ completed the survey. Forty four $(55.7 \%)$ respondents were females. In terms of physical environment of the skills laboratory, $62.8 \%$ of students were satisfied with the location of the clinical skills laboratory, $59.0 \%$ with the appropriateness of the educational atmosphere of the laboratory and $65.8 \%$ with the class size. Less than half of the students were satisfied with adequacy and appropriate use of educational equipments in the laboratory $(43.0 \%$ and $38.5 \%$, respectively). In terms of duration of clinical skills practice, $40.5 \%$ of students were satisfied with the frequency of clinical skills sessions and $46.2 \%$ with the time allocated for each session. Details of students' satisfaction with the physical environment of the clinical skills laboratory and the duration of clinical skills practice are shown in Table 1.

Table 1: Students' satisfaction with the physical environment of the clinical skills laboratory and the duration of clinical skills practice.

\begin{tabular}{|c|c|c|c|}
\hline \multirow[b]{2}{*}{ Statement } & \multicolumn{3}{|l|}{ Results (\%) } \\
\hline & $\begin{array}{l}\text { Strongly disagree/ } \\
\text { Disagree }\end{array}$ & No Opinion & $\begin{array}{l}\text { Strongly agree/ } \\
\text { Agree }\end{array}$ \\
\hline \multicolumn{4}{|l|}{ Physical environment } \\
\hline $\begin{array}{l}\text { I am satisfied with the location of the clinical skills } \\
\text { laboratory }\end{array}$ & 15.3 & 21.8 & 62.8 \\
\hline $\begin{array}{l}\text { The educational atmosphere of the clinical skills } \\
\text { laboratory is appropriate }\end{array}$ & 9.0 & 32.1 & 59.0 \\
\hline $\begin{array}{l}\text { The class size in clinical skills laboratory sessions is } \\
\text { appropriate }\end{array}$ & 13.9 & 20.3 & 65.8 \\
\hline The educational equipments are of good quality & 13.9 & 34.2 & 51.9 \\
\hline The number of educational equipments is adequate & 27.8 & 29.1 & 43 \\
\hline There is an appropriate usage of educational equipments & 18 & 43.6 & 38.4 \\
\hline \multicolumn{4}{|l|}{ Duration of clinical skills practice } \\
\hline $\begin{array}{l}\text { Duration of training in clinical skills laboratory is } \\
\text { appropriate }\end{array}$ & 21.6 & 27.8 & 50.7 \\
\hline The frequency of the clinical skills sessions is fair enough & 31.6 & 27.8 & 40.5 \\
\hline $\begin{array}{l}\text { The time allocated for each clinical skills session is } \\
\text { adequate }\end{array}$ & 15.4 & 38.5 & 46.2 \\
\hline
\end{tabular}


Concerning organization of clinical skills teaching sessions, $36.7 \%$ were satisfied with availability of structured and well explained guidelines on each skill station and $38.5 \%$ with appropriateness of course planning. Over half of the students were satisfied with the different aspects of instructors' performance. Details of students' perception of the quality of teaching in the clinical skills laboratory are shown in Table 2.

Table 2: Students' perception about the quality teaching in the clinical skills laboratory.

\begin{tabular}{lll}
\hline Statement & Results (\%) & \\
& $\begin{array}{l}\text { Strongly disagree/ } \\
\text { Disagree }\end{array}$ & No opinion \\
& $\begin{array}{l}\text { Strongly agree/ } \\
\text { Agree }\end{array}$ \\
\hline
\end{tabular}

Organization of sessions

The practice in clinical skills laboratory covers the common clinical skills

There is an appropriate course planning (including objectives, educational tasks and references)

The organization of the clinical skills sessions is appropriate

Guideline are available on each skill station and are structured and well explained

\section{Instructors' performance}

The instructors of clinical skills are friendly and helpful

The instructors have good experience

The instructors of clinical skills encourage students to actively participate in clinical skill sessions

The instructors of clinical skills advise the students about possible hazards of particular skill training

The instructors of clinical skills deliver information in organized and structured way
40.5

46.8

28.2

33.3

20.3

35.4

44.3

27.9

35.4

36.7

15.4

32.1

52.6

15.2

32.9

11.4

36.7

51.9

13.9

34.2

51.9

12.7

36.7

50.7 
In terms of usefulness of clinical skills laboratory, $78.1 \%$ of students preferred to take sessions and practice in the skills laboratory before dealing with real patients, $71.8 \%$ recognized the necessity of earlier integration of teaching in clinical skills laboratory in medical study curriculum, $71.2 \%$ had enjoyed practicing in the clinical skills laboratory and $69.9 \%$ agreed or strongly agreed that the clinical skills laboratory provides a safe environment to practice skills. Lower satisfaction was reported for the sufficiency of what the students were taught $(48.0 \%)$. Around $52 \%$ of students thought that practicing in the clinical skills laboratory rather than directly on patients will negatively affect students' communication skills. Details of students' perception about different aspects of usefulness of clinical skills laboratory are shown in Table 3.

Table 3: Students' perception about different aspects of usefulness of clinical skills

\begin{tabular}{|c|c|c|c|}
\hline \multirow[b]{2}{*}{ Statement } & \multicolumn{2}{|l|}{ Results (\%) } & \multirow[b]{2}{*}{$\begin{array}{l}\text { Strongly agree/ } \\
\text { Agree }\end{array}$} \\
\hline & $\begin{array}{l}\text { Strongly disagree/ } \\
\text { Disagree }\end{array}$ & No opinion & \\
\hline $\begin{array}{l}\text { Practice in clinical skills laboratory is helpful to } \\
\text { gain confidence }\end{array}$ & 8.2 & 27 & 64.9 \\
\hline $\begin{array}{l}\text { The clinical skills laboratory provides a } \\
\text { motivational environment to learn }\end{array}$ & 8.1 & 25.7 & 66.2 \\
\hline $\begin{array}{l}\text { The clinical skills laboratory provides safe } \\
\text { environment to practice skills }\end{array}$ & 4.1 & 26 & 69.9 \\
\hline $\begin{array}{l}\text { Practice in the clinical skills laboratory is } \\
\text { helpful to insure patient safety }\end{array}$ & 5.5 & 28.8 & 65.8 \\
\hline $\begin{array}{l}\text { Practicing in the clinical skills laboratory rather } \\
\text { than directly on patients will negatively affect } \\
\text { student's communication skills }\end{array}$ & 16.4 & 31.5 & 52 \\
\hline $\begin{array}{l}\text { I prefer to take the sessions in the skills } \\
\text { laboratory and practice before dealing with } \\
\text { real patients }\end{array}$ & 6.8 & 15.1 & 78.1 \\
\hline $\begin{array}{l}\text { I enjoyed practicing in the clinical skills } \\
\text { laboratory }\end{array}$ & 6.8 & 21.9 & 71.2 \\
\hline $\begin{array}{l}\text { I had enough opportunity to practice } \\
\text { clinical skills before having to use them on } \\
\text { real life patients }\end{array}$ & 13.9 & 30.6 & 55.6 \\
\hline $\begin{array}{l}\text { I think what I was taught in clinical skills is } \\
\text { sufficient }\end{array}$ & 20.5 & 31.5 & 48 \\
\hline $\begin{array}{l}\text { In hospital, doctors, nurses and patients } \\
\text { generally considered my clinical skills as good }\end{array}$ & 8.4 & 32.4 & 59.2 \\
\hline $\begin{array}{l}\text { Sometimes I was told that the way I was } \\
\text { taught was not the correct way of doing it }\end{array}$ & 19.7 & 38 & 42.3 \\
\hline $\begin{array}{l}\text { I feel the skills I was taught in clinical skills } \\
\text { laboratory are directly applicable to what I } \\
\text { need to do in the hospital }\end{array}$ & 9.8 & 32.4 & 57.7 \\
\hline $\begin{array}{l}\text { Teaching in clinical skills laboratory should be } \\
\text { integrated to medical curriculum at earlier } \\
\text { stages }\end{array}$ & 12.8 & 15.4 & 71.8 \\
\hline
\end{tabular}




\section{Discussion}

The relatively high non-response rate $(31.3 \%)$ is primarily attributed to having the data collection around the final examinations period where it was very hard to follow up or re-approach the non-respondents. Although the clinical skills laboratory was started in a temporary location away from the college of medicine, $62.8 \%$ of the students found the location to be appropriate. This could be attributed to the fact that only the final year students were taught in this laboratory. These students attend mostly teaching hospitals during their study time rather than the college and some of these hospitals are closer to the laboratory than the college. Similarly, having $59 \%$ of students being satisfied with the educational atmosphere and $65.8 \%$ with class size might also be attributed to the fact that only final year medical students currently use the laboratory. If teaching in clinical skills laboratory is integrated to the curriculum of earlier stages as it is currently planned, the students might have more concerns about the current location of the laboratory, the educational atmosphere and the class size. A similar study from Saudi Arabia also showed that $69.4 \%$ of students were satisfied with the location of the skills laboratory although the clinical skills laboratory was started in a temporary location. ${ }^{7}$ Having only $43 \%$ and $38.5 \%$ of students being satisfied with adequacy and appropriate use of educational equipments in the laboratory, respectively, could be attributed to the recent establishment of the laboratory and its equipping that was made over the study year. In a study from South Africa, students reported that the equipments in the laboratory were accessible and of reasonable quality. However, few students reported dissatisfaction with some of the equipment and requested that more equipment be made available. ${ }^{9}$ Low satisfaction with the duration of clinical skills practice particularly in terms of frequency of clinical skills sessions and time allocated for each session might reflect poor integration of clinical skills training into the curriculum and the possible need to earlier integration of clinical skills teaching into the curriculum rather than having it only during the final year of study. In a similar experience in Saudi Arabia, more than half of the students $(58.9 \%)$ found the duration of the sessions not enough and more than two thirds of the students $(82.3 \%)$ thought that more sessions were needed. ${ }^{7}$ Presence of clear goals and well-structured sessions are important preconditions for effective teaching in clinical skills laboratory. ${ }^{10}$ Having only $36.7 \%$ of students being satisfied with availability of structured and well explained guidelines on each skill station and $38.5 \%$ with appropriateness of course planning, could be attributed to the early and limited experience with teaching in clinical skills laboratory and lack of professional management of the laboratory. In contrary, a similar experience from Saudi Arabia and despite the short experience reported that $64.2 \%$ of students were satisfied with the organization of the sessions. ${ }^{7}$ Factors related to instructors' performance like good time management, consistency of teaching and the appropriate personal appearance of teachers have been identified as preconditions for effective teaching in clinical skills laboratory. ${ }^{10}$ Over half of the students were satisfied with the different aspects of instructors' performance. In a similar experience from Saudi Arabia, a much higher proportion of students $(82.1 \%)$ considered the instructors to be friendly and helpful. ${ }^{7}$ The relatively lower satisfaction in this study could be attributed to the new experience of the instructors and/or to the difference in definitions used to measure such satisfaction by the two studies. At this critical stage, there is a need for the instructors to participate in training courses on management and organization of clinical skills laboratory in order to improve this experience. The general effectiveness of clinical skills laboratory and students' high satisfaction 
with the overall usefulness of training on procedural skills using manikins is well documented. ${ }^{7,11}$ In this study, $67.6 \%$ of students recognized the general usefulness of clinical skills laboratory. Such positive perception of the skills laboratory is expected from these students as they had not such opportunity during their earlier study years to be trained in a structured way and to practice on manikins before going to wards and starting to practice on patients. Around $78 \%$ of students indicated their preference to take sessions in the skills laboratory and practice before dealing with real patients. Such preference has also been strongly emphasized by medical students from other contexts. ${ }^{7}$ Although students' satisfaction with the structure and organization of the training was relatively poor in this study, it is interesting to notice that $78 \%$ of students preferred to take sessions in skills laboratory before dealing with patients. This might indicate that students are generally positive about the concept of getting training in clinical skills laboratory. However, they highlighted important challenges that need to be addressed to improve this experience of clinical skills teaching and thus increasing their satisfaction. The necessity of integrating teaching in clinical skills laboratory to earlier stages of the medical study was emphasized by $71.8 \%$ of the students. Literature has documented the importance of early introduction of clinical skills teaching in the curriculum even from the first year. Studies have shown that the majority of medical students recognize the usefulness of introducing clinical skills in the early years of the curriculum. Clinical skills learning enhances the learning interest of early year students and make them feel like doctors. Early skills training is, in fact, a good preparation for later clinical and clerkship years, and as a way of lessening pressure in these years. ${ }^{12,13}$ Different positive aspects of training in clinical skills laboratory were recognized by the study participants including provision of safe, motivational and confidence-building environment to practice skills with insuring patient safety. Other studies have also recognized the positive role of this teaching strategy in facilitating skills acquisition, increasing students' confidence, and the long term help to bridge the theory-practice gap. ${ }^{14,15}$ However, only $48 \%$ of the study participants were satisfied with sufficiency of what they were taught of clinical skills. This could most possibly be attributed to lack of such training opportunity during earlier years of study. Moreover, the students had already raised concerns about poor session plans, lack of proper guidelines and inadequate duration of training sessions as mentioned above. In fact, clinical skills laboratories do lead to improvement in procedural skills compared to standard or no training at all. However, there is a lack of well designed trials addressing the crucial issues of transferability to clinical practice and retention of skills over time. ${ }^{16}$ Around $52 \%$ of the study participants had concerns about the negative effect of practicing in the clinical skills laboratory rather than directly on patients on their communication skills. It is generally agreed that although clinical skills laboratory can provide a pathway to practice and its authenticity is significant, teaching strategies need to incorporate communication as well as psychomotor skills. Including audiovisual recording into assessment strategies is beneficial. In fact, effective relationships between educational institutions and clinical settings are needed to enhance the transferability of the skills learned. ${ }^{17}$

\section{Conclusion}

This short and new experience of training in clinical skills laboratory was positively recognized in general. This study might indicate that Hawler Medical University has taken an important and successful step toward teaching clinical skills in an effective way. However, shortcomings in a number of aspects were identified that need to be addressed to improve the experience. There are still substantial 
efforts required to achieve effective clinical skills teaching including earlier integration of clinical skills teaching in the study curriculum, the use of students' log book and progress monitoring report, application of objective structured assessment of learnt skills and not allowing students to practice on real patients before successfully passing such assessment. Further research is needed to adequately assess this experience once teaching in clinical skills laboratory is well established and adequately integrated into earlier stages of curriculum.

\section{Conflicts of interest}

The authors report no conflicts of interest.

\section{References}

1. Stark P, Fortune F. Teaching clinical skills in developing countries: are clinical skills centres the answer? Educ Health 2003; 16(3):298-306.

2. Ahmed AM. Role of clinical skills centers in maintaining and promoting clinical teaching. Sudanese Journal of Public Health 2008; 3(2): 97-103.

3. Lund F, Schultz JH, Maatouk I, Krautter M, Möltner A, Werner A, et al. Effectiveness of IV cannulation skills laboratory training and its transfer into clinical practice: A randomized, controlled trial. PLoS One 2012; 7(3):32831.

4. Lehmann R, Bosse HM, Simon A, Nikendei C, Huwendiek S. An innovative blended learning approach using virtual patients as preparation for skills laboratory training: perceptions of students and tutors. BMC Med Educ 2013; 13:23.

5. Developing medical and nursing skills in Iraq: Cardiff University and Hawler Medical University train new generation of Iraqi medics. (Accesses December 3, 2013), available from http://www.britishcouncil.org/ b466b_delphe_case_study_cardiff_aw.pdf

6. Tekian A. Have newly graduated physicians mastered essential clinical skills? Med Educ 2002; 36(5):406-7.

7. Soliman MM, Fouda K. Students' perception of one year experience with the clinical skills laboratory at King Saud University Medical College. Journal of Taibah University Medical Sciences 2008; 3(2):140-7.

8. Ziaee V, Ahmadinejad Z, Morravedji AR. An evaluation on medical students' satisfaction with clinical education and its effective factors. Med Educ Online 2004; 9:8.

9. Saakane K, John M, Timothe'e S, Maphosa M, Jennifer C, Petra B. Student evaluation of a clinical self-study laboratory. Nurse Educ Pract 2008; 8(5):359-67.
10. Duvivier RJ. Teaching and learning clinical skills: Mastering the Art of Medicine [PhD thesis]. Maastricht: Maastricht University; 2012

11. Hao J, Estrada J, Tropez-Sims S. The clinical skills laboratory: a cost-effective venue for teaching clinical skills to third-year medical students. Acad Med 2002; 77(2):152.

12. Omer R, Amir AA, Ahmed AM. An experience in early introduction of clinical teaching in a clinical skills laboratory. Sudanese Journal of Public Health 2010; 5(2):29-31.

13. Lam TP, Irwin M, Chow LW, Chan P. Early introduction of clinical skills teaching in a medical curriculum--factors affecting students' learning. Med Educ 2002; 36(3):233-40.

14. Hilton $P$. Clinical skills laboratories: teaching practical nursing. Nurs Stand 1996; 10(37):44-7.

15. Weyrich P, Schrauth M, Kraus B, Habermehl D, Netzhammer N, Zipfel S, et al. Undergraduate technical skills training guided by student tutors-analysis of tutors' attitudes, tutees' acceptance and learning progress in an innovative teaching model. BMC Med Educ 2008; 8:18.

16. Lynagh $M$, Burton $R$, Sanson-Fisher $R$. A systematic review of medical skills laboratory training: where to from here? Med Educ 2007; 41:879-87

17. Houghton CE, Casey D, Shaw D, Murphy K. Staff and students' perceptions and experiences of teaching and assessment in Clinical Skills Laboratories: interview findings from a multiple case study. Nurse Educ Today 2012; 32(6):29-34. 